Article

\title{
Electric Scooter Sharing and Bike Sharing User Behaviour and Characteristics
}

\author{
Tomasz Bieliński * ${ }^{\mathbb{D}}$ and Agnieszka Ważna \\ Faculty of Economics, University of Gdansk, Armii Krajowej 119/121, 81-824 Sopot, Poland; a.wazna@ug.edu.pl \\ * Correspondence: t.bielinski@ug.edu.pl; Tel.: +48-5004-799-53
}

Received: 9 October 2020; Accepted: 13 November 2020; Published: 19 November 2020

check for

updates

\begin{abstract}
New, shared mobility modes, including dockless e-scooters and e-bikes, were recently introduced to many cities around the world. The aim of this article is to determine the differences between the users of e-bike sharing, and e-scooter sharing systems, and the characteristics of their travel behaviour. This study is based on the survey of the citizens of Tricity in northern Poland. We find that e-bicycles are predominantly used as first and last mile transport and to commute directly to various places of interest, whereas e-scooters are more often used for leisure rides. Survey respondents that adopted shared micromobility are generally young, and e-scooter users are on average younger than e-bike users. Although all shared vehicles in Tricity are electrically assisted, this did not allow for the elimination of the gender gap, or help retired and disabled people in the adoption of shared micromobility services. We have also identified factors discouraging people from the usage of e-bike and e-scooter sharing and found them to be different for both types of services. Finally, we investigated the issue of using shared e-bikes for urban logistics.
\end{abstract}

Keywords: electric bike sharing; e-bike; e-cargo bike; e-scooter; scooter sharing; micromobility; passenger behaviour; urban mobility; urban logistics

\section{Introduction}

Throughout the world, cities have adopted bike sharing services to their transportation systems to ease problems arising from the use of private cars. Recently, new means of micromobility appeared in the city streets. Companies providing dockless, electrically-assisted scooter (e-scooter) sharing services introduced their offer to over 100 cities in the USA [1] and many other municipalities all over the world. Gradually bike sharing operators enrich their fleets with electrically assisted bicycles (e-bikes). Various types of personal transporters can be purchased or rented in most of the big cities around the world. Urban planners and municipal authorities need to consider the needs of this new type of micromobility user when they are developing infrastructure and creating new policies for these transportation modes. To successfully perform these tasks, they need to know the characteristics of these new groups of people, their travel patterns, needs and motives of their actions. Thus, our study has been conducted to give an outline of these characteristics and show similarities and differences between e-scooter sharing and e-bike sharing systems. It was also necessary to indicate if these services are substitutes or complementary services, and what should be interesting from operators' and municipal authorities' perspectives. We have also discussed the theoretical background on the potential of micromobility shared services for cargo transport-this could improve sustainable urban logistics.

The aim of our study was to determine the differences between the users of e-bike sharing, and e-scooter sharing systems, and the characteristics of their travel behaviour. We have also investigated what discourages citizens from the wider use of electric micromobility sharing systems and discussed the problem of integrating electric bike sharing systems (BSS) with cargo-friendly solutions. Identification of these factors may be useful not only for local, but for all operators and 
transport policy makers who want to organise micromobility systems in cities accordingly to users' preferences. This is also interesting from the municipal authorities' perspective, due to their role in organising entirety of public transportation systems which nowadays are facing the challenge of integration with micromobility services.

Two types of personal light electric vehicles sharing systems were introduced to the market of Metropolitan Area Gdansk Gdynia Sopot (informally called "Tricity") in 2019. The first one was a public bike sharing system (BSS) called MEVO, equipped with the fleet of 1224 e-bikes, funded by the metropolitan authorities. The second type comprised e-scooter sharing systems provided by three private competing companies. At that time, no solutions supporting cargo transport and integrated with micromobility services were implemented. Tricity was the only metropolitan area in Europe in which the only BSS introduced was electric, and did not include any conventional bikes. That gave us unique opportunity to compare the behaviour of users of shared e-bikes with shared e-scooters in the same environment.

\section{Literature Review}

Shared micromobility services, including electric bicycles and scooters, have significant impact on passengers' travel decisions and behaviour. They are considered as convenient modes of transportation, especially when they are dockless and electrically assisted [2,3]. There are several studies focusing on micromobility and its potential to support first and last mile connectivity with public transport [4-8]. Growing accessibility of shared micromobility services is supporting municipal authorities in overcoming problems affecting urbanised areas. These problems are external transportation costs, traffic congestion, air pollution, space occupation (by cars) and car accidents [9-12]. Using shared e-scooters and e-bikes as a tool to achieve sustainable urban transportation requires making them available to as many social groups as possible. Improvements in BSS, such as cargo-bikes and bicycle trailers that may be provided by operators, fit into the concept of low carbon city logistics and are seen as an effective tool in overcoming transportation problems in urbanised areas [13].

There are few scientific publications investigating the usage of a shared e-scooter as it is an emerging type of micromobility service. A research report on the adoption of e-scooters published by Populus [14] shows that $70 \%$ of citizens of major cities in the U.S. express positive attitude towards this type of micromobility. Moreover, the study suggests shared electric scooters to be more easily adopted by women than regular bike sharing services, which may help to reduce the existing gender gap in shared micromobility usage in general. The gender gap has been also described by Akar et al. [15], Murphy and Usher [16]. Results from the survey in the city of Tempe (Arizona, US) on the University staff show that e-scooters were used by $36 \%$ of the respondents and are seen as a convenient mode of transportation compared to walking (especially in high temperatures typical of the Arizona climate). The same study shows that there are demographic differences in factors that discourage people from using e-scooters. Women are much more concerned about traffic safety issues than men, and African-American and non-white Hispanic respondents are more likely to try e-scooters than non-Hispanic white respondents. Interestingly, the study shows that e-scooters were more frequently used to commute than for recreation [17].

Some differences between particular shared micromobility services in terms of usage patterns have been identified by McKenzie [18]. His research is focused on comparison of dockless e-scooters and station-based bike sharing services in terms of spatial and temporal activity patterns. Study shows that there are substantial differences in reasons to use BSS and shared e-scooters in Washington D.C. Managed and supported by government, station-based public bicycles are mainly used to commute to work or school, while newer and private e-scooter sharing services are more often used for touristic and recreational trips. A study conducted by He et al. [19] in City Park, Utah, discovered that shared e-bikes are more often used for recreation than to commute to work. Another study, based on providing six e-scooters to 38 people in Munich showed that trips made by this group of users were mainly for leisure and subsequently shopping and commuting purposes [20]. One study conducted in Groningen 
(The Netherlands) showed that e-bikes were most often used in work-related, single-destination journeys [21].

The studies investigating characteristics of shared micromobility users bring similar results. Most of them indicate that the users are generally well-educated, younger adults between 21-45 years old, with middle and upper income, and no children, living in urban build environments with limited access to private cars [2,22]. Referring to dockless shared e-scooters and bicycles, there are examples of cities where these services were used by more diverse user bases than in cities with station-based systems. Dockless vehicles might be more available in underserved areas, and thus be easier to use by different groups of users. The study conducted by Zhang et al. [6] that the peripheral city zones of Zhongshan (China) are characterised by low bicycle usage and low market penetration by BSS operators.

Although the existing literature examining dockless and electrically assisted scooters' users is limited, there are studies documenting characteristics of people using BSS. A study based on New York's Citi Bike system data revealed that most bike sharing trips were made by those born between 1979-1988 (Older Millennials), who are more often employed making more commuting trips to work than younger people. At the same time, they easier and faster adopt shared mobility services than older age-cohorts [5]. The study conducted by Chen et al. [23], based on comparative analysis of two types of BSS (station based and free floating), shows that users characteristics for both types of systems are similar. BSS users in Hangzhou (China) are mostly younger than 35, they do not own a car or an e-bike and have at least a bachelor's degree.

Potential bike sharing usage barriers were identified by Nikitas [24]. His research based on survey of 640 responses shows that road safety concerns and lack of cycling infrastructure are main factors that discourage citizens from using BSS. Another study confirms that longer bicycle paths nearby bike sharing stations are an encouragement for BSS users to choose a public bike [25]. Some studies indicate weather conditions to be a factor that influences bike sharing users' trip decisions. Rainfall, snowfall, low temperature, high wind speed and humidity are classified as BSS usage barriers [5,26-28]. Further research conducted by Nikitas [29] identifies bicycle ownership, lack of sufficient bike sharing and cycling infrastructure, weather conditions, hilly terrain and road safety concerns as main reasons not to use BSS frequently or at all.

As mentioned above, people who have small children do not adopt shared mobility services. Interestingly, the research made by Bjørnarå et al. [30] suggests that providing easy access to e-bikes for parents who have children in kindergarten might result in increased cycling, even during wintertime. Electrically assisted bicycles were also identified as a mean of transportation, supporting trips made in hilly terrain city areas. It has been confirmed by He et al. [19] that average travel distance for e-BSS in Utah was $5 \mathrm{~km}$, regardless of the terrain. It also implies that e-bikes are encouraging BSS users to travel longer distances in comparison to trips made on ordinary bikes [5].

In the existing literature, there are no studies that compare user characteristics and behaviours of e-bike BSS with e-scooter sharing services. Moreover, most of the studies concerning the usage of BSS or shared e-bikes are based on case studies of systems operating in a given city. Our study intends to confirm or disprove findings in regard to the conditions of the Polish metropolis.

\section{Background}

Metropolitan Area Gdansk Gdynia Sopot (Tricity) is located in the north of Poland, on the coast of the Baltic Sea. These three cities and their neighbouring municipalities are an urban area with over 1 million inhabitants. Demographic statistics show that society of the Pomorskie Voivodeship, where Tricity is located, is gradually ageing. In 2018, the share of elderly people (65 plus years) in the total population of this region was $16.4 \%$. This indicator has increased by 0.5 percentage points from 2017 and 4.5 percentage points from 2005. In 2018, the median age in Pomorskie was 36.9 years (4.3 years more than in 2005) [31]. The development of bicycle and other types of micromobility infrastructure is determined by the fact that Tricity is situated in a hilly area. Its specific topography, 
shaped by hills and being within the neighbourhood of the Baltic Sea coast, cause some difficulties in transportation infrastructure planning. However, the municipal authorities of Tricity support the improvement of urban transport system including development of infrastructure for micromobility. The length of bicycle paths is increasing, and transport interchanges are being renewed and adapted to the needs of various groups of passengers. Passenger information systems are being gradually implemented and public transport services are going through a process of integration in terms of pricing and payment system [32,33]. Introducing MEVO (electric bike sharing system financed by metropolitan authorities) was one of the planned steps to support sustainable development of Tricity's transportation system. All these changes were also planned to address the transportation needs of elderly and disabled citizens.

MEVO-Tricity's bike sharing system managed by subsidiary of Nextbike, the leading company in the European bike sharing market [34] —was launched in March 2019. At that time, it was the first fully electric BSS in Europe with a planned fleet of 4080 vehicles. Furthermore, the system was based on the hybridized model being partially dockless (users had the possibility to drop vehicles outside the stations for an additional fee). Eventually, only 1224 e-bikes were delivered before the system shut down in October 2019 [32]. The operator was bankrupt despite the popularity of the e-BSS among the citizens. MEVO reached 2.06 million trips and 167 thousand registered users after 185 days of operation [35]. The TDB indicator (trip per day per bike) for MEVO was 9.1, which was very high compared with the mean TDB in Polish bike sharing systems in 2018 (1.93 TDB). In fact it would be higher than in the best performing systems that were operating in Poznan (4.89 TDB) and Wrocław (4.88 TDB) [26]. There are various reasons for the collapse of MEVO. The system's operator, despite being experienced in BSS management, had not anticipated problems with a relatively big system that was not only fully electric, but also with it being partially free-floating. Costs of implementation and maintenance, including charging batteries and rebalancing the fleet, exceeded the budgetary capacity largely determined by the municipal authorities. As maximum prices were set by the terms of the public tender, MEVO's operator could not adjust prices of the service to control the demand and revenues. Users had to pay 0.1 PLN per minute of rental. They could also make the subscription for 10 PLN per month or 100 PLN per year with 90 min usage every day, without additional fee [36].

In Tricity, shared electric scooters appeared in May 2019. Three private operators (Blinkee.city, Quick Ride and Logo-Sharing) initially delivered about 540 vehicles (respectively, 100, 250 and 190) to the streets of Gdansk and shortly afterwards expanded their services to Gdynia and Sopot [37-39]. Shared e-scooters can reach maximum speed of $25 \mathrm{~km} / \mathrm{h}$ due to Polish regulations of low-speed vehicles. The average speed (including stops, traffic lights and passing pedestrians) is about $10-15 \mathrm{~km} / \mathrm{h}$ which is twice as fast as a regular walk [39]. The range with a fully charged battery is about $35 \mathrm{~km}$ [38]. Each operator allows the user to rent e-scooters by using a mobile application. These services are more expensive than average public transport services in Tricity, comparing the prices for the same trip distance. For example, the user pays around 10 PLN for a $3 \mathrm{~km}$ ride on an e-scooter ( 2.5 or 3 PLN flat fee and 0.49 or 0.50 PLN per minute, depending on the operator) [37-39]. This price is about three times higher than a ticket for a bus or tram in the city of Gdansk. All of three shared e-scooter services' operators are companies registered in Poland. Two of them are start-ups, and only Blenkee.city has any experience, as they have been providing e-mopeds in the Polish shared mobility market since March [40].

\section{Data}

Data collection was carried out by the MRC Consulting company using the Computer-Assisted Personal Interviewing technique (CAPI) on the random sample of 633 respondents, between 21 August 2019 and 27 September 2019. In that period both MEVO and e-scooter sharing systems were fully operational. The data were collected in the metropolitan area of three major cities Gdansk, Gdynia, Sopot, and 11 neighbouring municipalities, where the MEVO system was functioning. A series of 
preliminary in-depth interviews with users of MEVO, and shared e-scooter users conducted by the authors helped in developing the survey questions used in this study. Additionally we built our questionnaire, previously analysing recent studies examining bike sharing and e-scooter sharing users' preferences that have been based on similar research tools $[17,41,42]$. Once the survey design was completed and prior to distribution to the sampling frame, a pilot study was undertaken on 17 people. The main purpose of the survey was to identify user characteristics and reasons to use both types of sharing systems and disincentives for using MEVO and in relation to shared e-scooters. The data were processed using SPSS software.

\section{Results}

Fifty one percent of respondents reported using MEVO and 8.8\% shared e-scooters. E-bikes were also used more frequently. Only $0.3 \%$ of surveyed citizens used e-scooters on the daily basis while MEVO was used every day by $2.1 \%$ of respondents. Most of the respondents used e-scooters only a few times a year (see Figure 1). Significantly smaller adoption rates of electric scooters in comparison to bike sharing services were reported also in American cities. The study by Populus [14] shows $3.6 \%$ adoption rate of e-scooters and $13 \%$ of station-based bike sharing (measured by the percentage of people who have ever used these services). Station-based bike sharing cannot be compared with MEVO system, that was equipped with e-bikes only and was partially free-floating, and therefore much more comfortable in use.

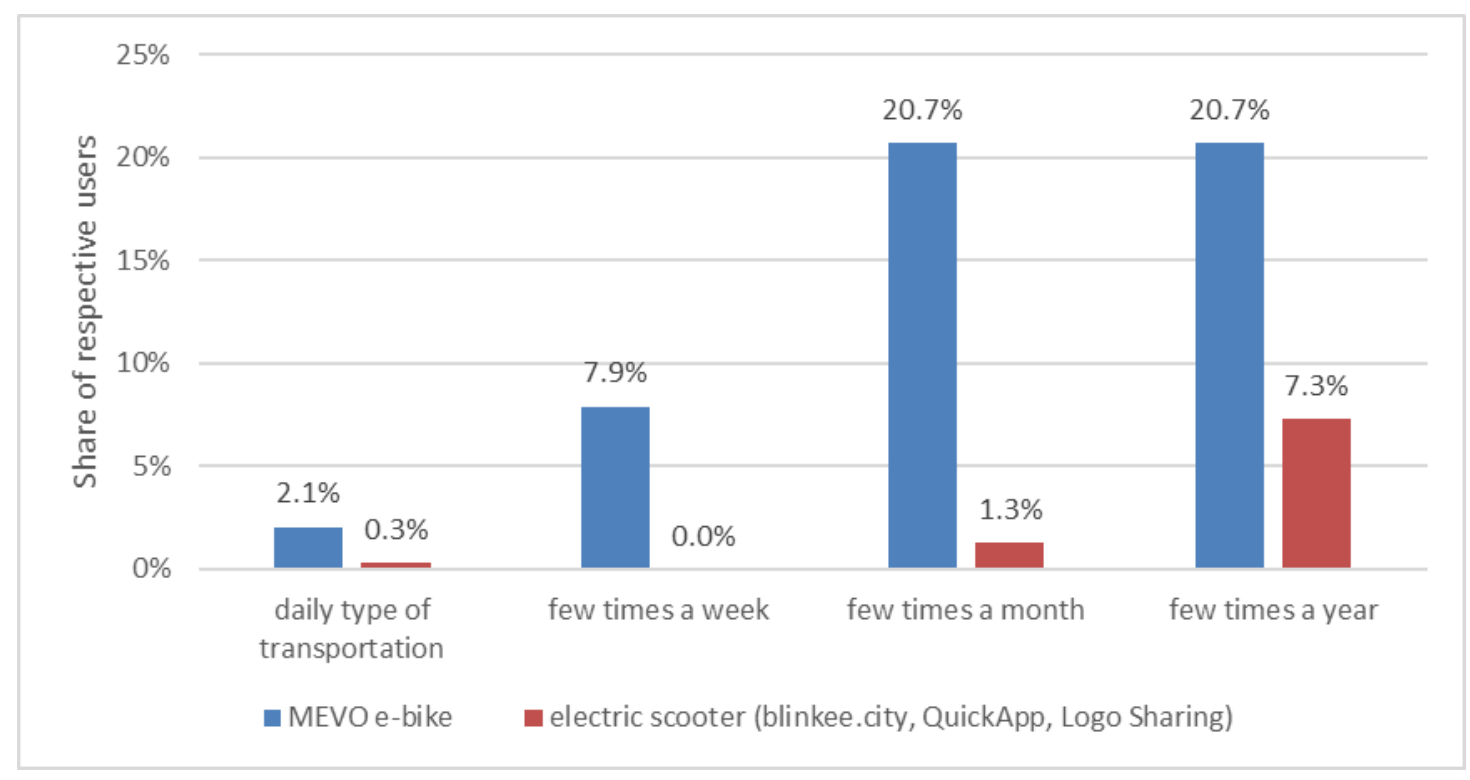

Figure 1. Frequency of use of MEVO e-bikes and electric scooters.

The mean age of both MEVO e-bike users and electric scooter sharing users is lower than the mean age of surveyed citizens. However, the difference in age is bigger in the case of scooter sharing users, who are on average 3 years younger than MEVO users. The oldest person to use MEVO was 69, and the oldest to use scooter sharing was 52 (see Table 1).

As it was expected, we found gender-based disparities in the usage of both types of services. These kinds of differences were also found in the studies by Akar et al. [15], Murphy and Usher [16]. In the Populus [14] research report disparities between men and women were bigger in the case of bike sharing than in the case of scooter sharing. Our results suggest opposite dependence. Only $37.5 \%$ of scooter sharing users in our survey were woman, while for the e-bike sharing system MEVO it was $45.8 \%$. 
Table 1. MEVO and e-scooter sharing user characteristics—descriptive statistics.

\begin{tabular}{|c|c|c|c|}
\hline & Surveyed Citizens & MEVO E-Bike Users & Scooter Sharing Users \\
\hline $\mathrm{N}$ & 633 & 325 & 56 \\
\hline \multicolumn{4}{|l|}{ Age } \\
\hline Mean & 35 & 34 & 31 \\
\hline Standard deviation & 10.0 & 9.3 & 8.5 \\
\hline Maximum & 73 & 69 & 52 \\
\hline Minimum & 13 & 16 & 16 \\
\hline \multicolumn{4}{|l|}{ Gender } \\
\hline Woman & $47.6 \%$ & $45.8 \%$ & $37.5 \%$ \\
\hline Man & $52.4 \%$ & $54.2 \%$ & $62.5 \%$ \\
\hline Median income (in PLN) & 3380 & 3336 & 3205 \\
\hline \multicolumn{4}{|l|}{ Vehicle ownership } \\
\hline Bicycle ownership & $91.9 \%$ & $91.7 \%$ & $89.3 \%$ \\
\hline Motorcycle ownership & $4.6 \%$ & $4.6 \%$ & $3.6 \%$ \\
\hline Car ownership & $65.7 \%$ & $63.4 \%$ & $58.9 \%$ \\
\hline Scooter ownership & $12.6 \%$ & $13.2 \%$ & $19.6 \%$ \\
\hline E-scooter ownership & $2.5 \%$ & $3.4 \%$ & $8.9 \%$ \\
\hline Other personal light electric vehicle ownership & $3.0 \%$ & $2.2 \%$ & $1.8 \%$ \\
\hline \multicolumn{4}{|l|}{ Employment status } \\
\hline Student & $16.3 \%$ & $18.5 \%$ & $30.4 \%$ \\
\hline Employed & $88.5 \%$ & $89.8 \%$ & $82.1 \%$ \\
\hline Unemployed & $1.4 \%$ & $1.2 \%$ & $0.0 \%$ \\
\hline Homemaker & $5.2 \%$ & $3.4 \%$ & $7.1 \%$ \\
\hline Retired & $1.4 \%$ & $0.9 \%$ & $0.0 \%$ \\
\hline Unable to work & $0.6 \%$ & $0.6 \%$ & $0.0 \%$ \\
\hline Driving license holders & $86.6 \%$ & $87.7 \%$ & $82.1 \%$ \\
\hline
\end{tabular}

We did not find a significant difference in the income of MEVO or electric scooter sharing users. Modal income of electric scooter sharing users is lower than MEVO users, but this may be associated with their age and employment status, as many of them are students (30.4\%). The share of students was significantly lower in case of MEVO users-18.5\%. Most of the survey respondents were employed $(88.5 \%)$, and so were the users of MEVO (89.8\%); the share of employed electric scooter sharing users was $82.1 \%$. This may also be associated with their younger average age. Survey respondents included $1.4 \%$ pensioners, and $0.6 \%$ people that are unable to work, but among MEVO users there were $0.9 \%$ pensioners, and $0.6 \%$ people that are unable to work. There were no people with disabilities or pensioners surveyed that would use electric scooter sharing services.

Among all survey respondents $12.6 \%$ own scooters and 2.5\% electric scooters. However, scooter and electric scooter ownership rates by the people that used electric scooter sharing services were $19.6 \%$ and $8.9 \%$, respectively. This may lead to the conclusion that people that already own scooters, and know how to ride them, are more willing to rent them. Therefore, further popularization of e-scooters may lead to bigger demand on scooter sharing services.

As car ownership rate is smaller among younger citizens, as they seek alternative methods of transportation. They are more likely to own private scooters or e-scooters and be willing to use shared scooters. Good quality e-scooter sharing services and comfortable infrastructure may allow them to keep their sustainable transportation habits when they grow older.

Surveyed users of MEVO used e-bikes to cycle to a variety of destinations and for different reasons (see Figure 2), while shared e-scooters users pointed to less destinations. This was expected, as most of the e-scooter users used them only once. E-bikes were used as a first-last mile mean of transportation by $71.7 \%$ of their users, while only $30.4 \%$ of e-scooter users rode them to get to (or from) public transportation stops. The most common reason to use shared e-scooter (appointed by $51.8 \%$ of users) was just to have fun riding it. This was placed as the eighth reason for the use of MEVO. In case of e-scooters our results are similar to those obtained by Hardt and Bogenberger [20], who found that 
e-scooters (rented for long term, not in sharing system) were 33\% used for leisure trips, $24 \%$ shopping related trips, $19 \%$ commuting trips, and 12\% errand trips. E-scooters were also used for business trips (5\%), while $7 \%$ of trips were for pickup/drop-off. Similar to our results, Hardt and Bogenberger [20] also found that most of the scooters were used only occasionally by the majority of users.

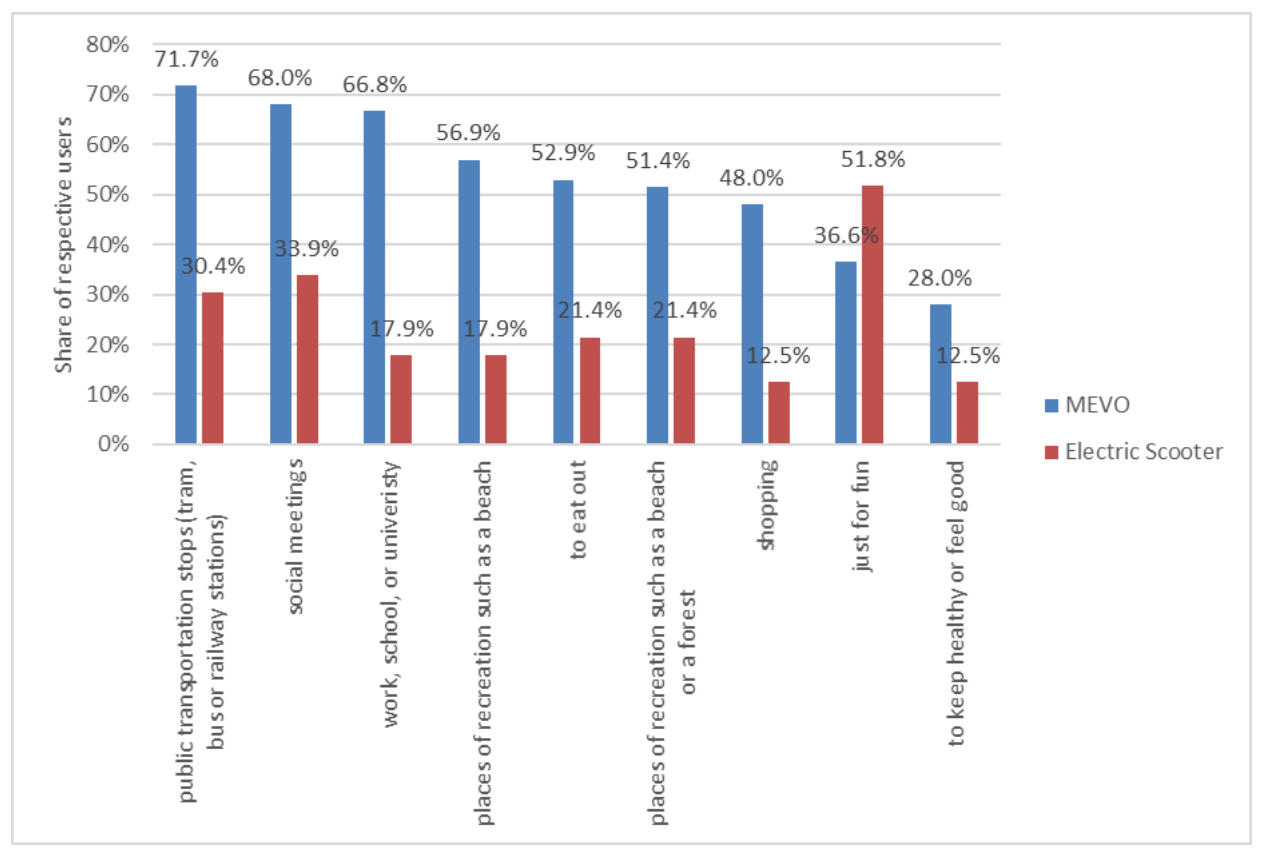

Figure 2. Trip purposes of MEVO or Electric Scooter sharing users (users of each mode of transportation could choose more than one trip purpose).

Micromobility can become a solution for several urban transportation problems (like congestion and air pollution), only if it is used on a daily basis. In the Tricity area, electric scooter sharing was used only occasionally, and rather for fun or to meet with friends, than to commute to work or school. To elucidate the reasons why shared e-bikes were more popular than scooters we have identified factors discouraging people from the usage of both means of transportation.

In our survey we asked respondents (both users and non-users of MEVO BSS and shared e-bikes) about the factors that discourage them from using the services of e-scooter sharing companies. It was a ranking question, where respondents had to choose which obstacles were of the highest importance. We attributed the highest weight to the first answer and correspondingly lower weights to further responses. Weighted answers of shared e-scooter users are presented in Figure 3.

The main reasons that discouraged e-scooters users were high fees, availability (not enough or no scooters available in right locations) and safety concerns. The main barriers for the people that never used this kind of service perceived no need to use them, high prices and safety concerns. Additionally, $12.2 \%$ of people never used e-scooter sharing services and never tried to ride a scooter and/or did not want to learn it (Figure 3). Quality and durability were not seen as major obstacles by the majority of respondents. Lower prices and improved availability could lead to higher usage of this kind of service. E-scooter rates in 2019 in Tricity were a 2.50 PLN flat fee plus 0.49 PLN per minute (Blinkee.city) and 3 PLN flat fee plus 0.50 PLN per minute (QuickApp and Logo-Sharing). Renting the MEVO e-bike was much cheaper, with 0.1 PLN per minute. It was also possible to use MEVO on the subscription basis with 10 PLN per month or 100 PLN per year, with 90 min of usage every day, free of additional charges.

Relatively low prices of MEVO services caused high demand, that was reflected in low availability of shared e-bikes. That is why the prevailing first answer to the question of what discouraged users of the BSS was the lack of bicycles (Figure 4). It was also the second most important barrier for the people that never used MEVO. In contrast to scooters, many people own bicycles, and therefore do not feel the need to rent them. This was the first reason not to use MEVO among non-users. In the 
case of e-bikes, there is a big difference between the first and weighted answers to that question. Availability of MEVO was the first concern of the people that wanted to use it, but when they were able to do that, other problems appeared. As e-bikes were used 9.1 times per day, durability and quality of the bicycles became a one of the major problems both for users and non-users of the system (as non-users could observe parked, but unavailable bicycles marked with flashing red lights). For 2.8\% of respondents, the first appointed obstacle to use MEVO was that they were not able to ride with children, as bicycles were not equipped with child seats. This could be partially solved if some part of the fleet was equipped with cargo-trailers adopted to transport children. Surprisingly, the inability to rent a bicycle helmet was not treated as a major problem, although $38.1 \%$ of respondents claimed that they always or almost always ride bicycles wearing helmets.

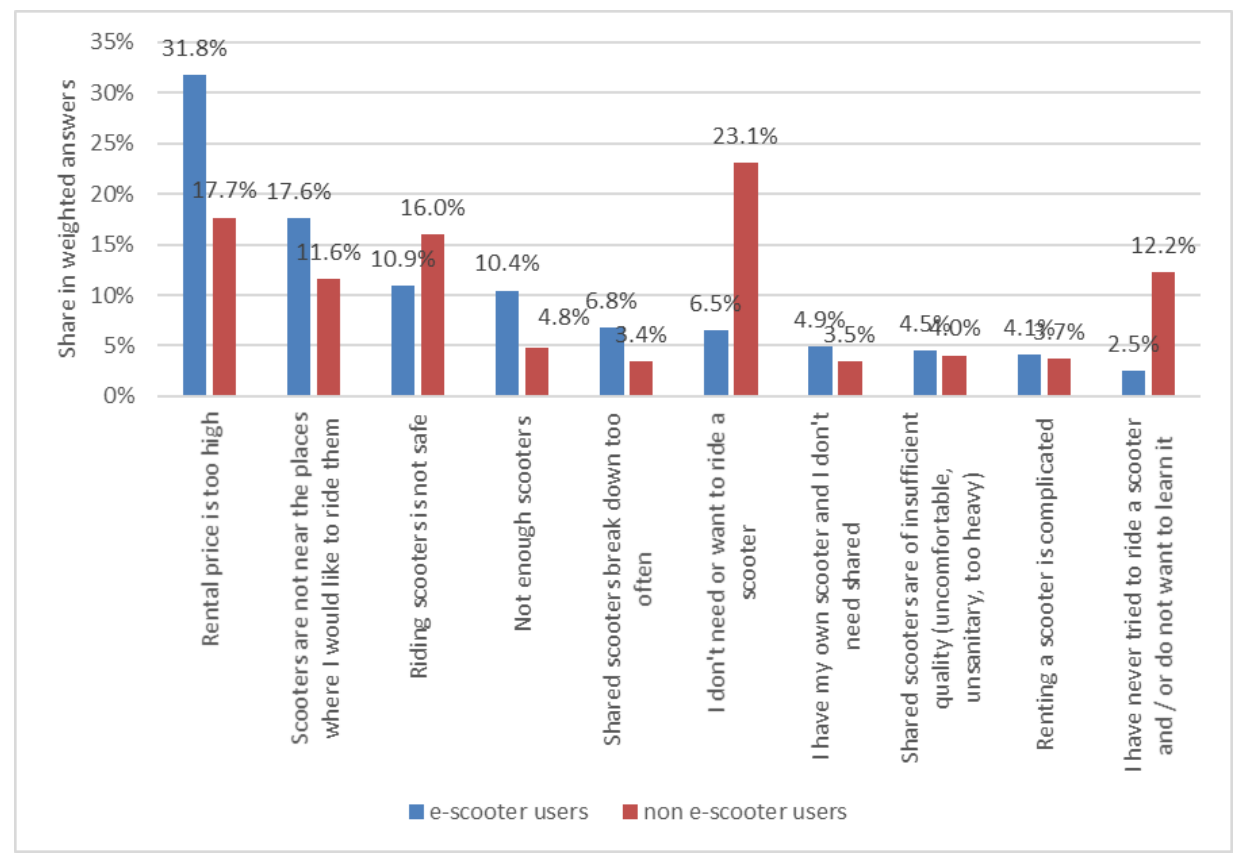

Figure 3. Factors discouraging from the use of e-scooter sharing systems.

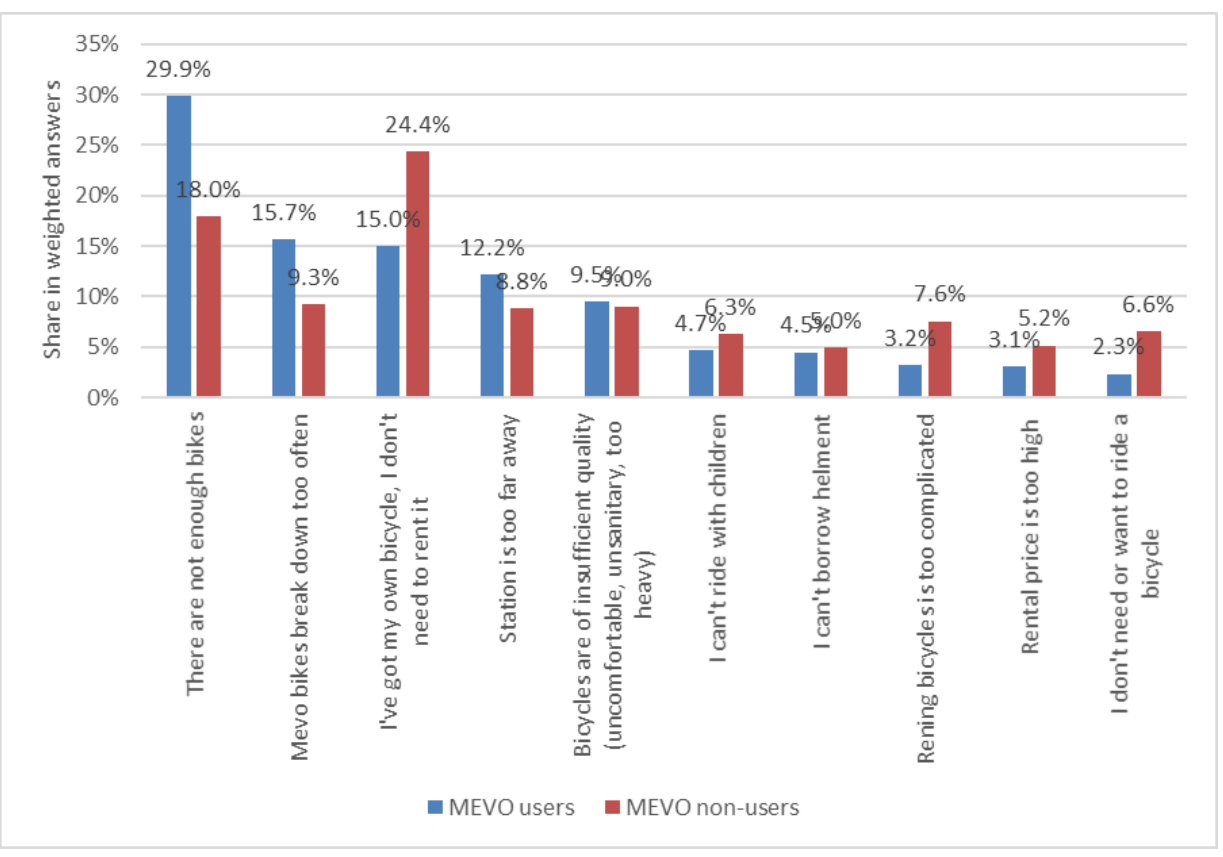

Figure 4. Factors discouraging from the use of MEVO e-bikes. 


\section{Potential of Electric Bike Sharing in Urban Logistics Improvement}

Discussing the characteristics of electric shared vehicles and their users, it is worth noting recent innovations supporting sustainable transportation in cities, including those tackling the negative effects of urban freight transport. Examples of such solutions are cargo-bikes and electric cargo-bikes. In the years 2013-2016 Pro-E-Bike-a project funded under the Intelligent Energy Europe programme-demonstrated "the environmental and social effectiveness and the economic profitability of e-bikes and e-scooters for urban logistics in substituting traditional combustion engine vehicles" [43]. Mode shift from combustion engine vehicles to electric cargo bikes in urban areas has been suggested by the German Federal Ministry for the Environment [44]. E-cargo bikes seem to be crucial for the European Commission's goal to "achieve essentially $\mathrm{CO}_{2}$-free city logistics in major urban centres by 2030" [45]. Even though these vehicles are not novelty and have been widely described in the literature [46-50], e-cargo bike sharing systems are rare, but with the potential to evolve. Hess and Schubert [51], in their recent study, investigate the perception of e-cargo bike sharing in Switzerland. They show barriers in the adoption of this solution among different groups of users. They also identify the system as a low-carbon transportation innovation which makes e-cargo bike sharing an important element of the green urban logistics concept.

MEVO bicycles were equipped with bicycle baskets attached to the bicycle handlebars; however, it was not designed to carry loads and was inconvenient to transport bigger goods. Additionally, the regulations prohibited the use of bicycles for commercial purposes. Despite the provisions in the regulations, MEVO bikes were used commercially, most commonly by food delivery couriers [52]. It was frowned upon but tolerated by the operator of the fleet. In one of the interviews, the operator's representative said: "If the rider uses the bike in accordance with other regulations, the operator does not impose fines and does not charge additional fees to people who use the bikes for commercial activities" [52]. This statement leads to the conclusion that the cargo-friendly bicycle solutions are not only desirable from the perspective of private and commercial users, but also accepted and may be supported by operators and municipal authorities. One of the main barriers to overcome on the way to introduce such solutions is lack of standardized legislation concerning safety issues and rules for the cargo equipment usage and rental. This problem has been already identified in Brazil [53].

Shared e-bikes designed for small goods deliveries could widely benefit the sector of food and last-mile parcel deliveries. It would also help to reduce the carbon footprint of the food delivery sector, as it is served mainly by cars or mopeds usually equipped with combustion engines [54]. The usage of e-bikes instead of cars also reduces the need for parking space and illegal parking problems. MEVO could change the way courier companies operate in the Tricity area, but the system ceased to exist before the introduction of cargo solutions was possible.

To fully exploit potential benefits of shared e-bikes for last-mile parcel deliveries, they should be equipped with comfortable luggage carriers or additional cargo-trailers that could be available for rent. In fact, such devices were already designed for the MEVO type shared bicycle. Cargo-trailers invented by Jan Libera (see Figure 5) could be used, but they were never introduced to the market.

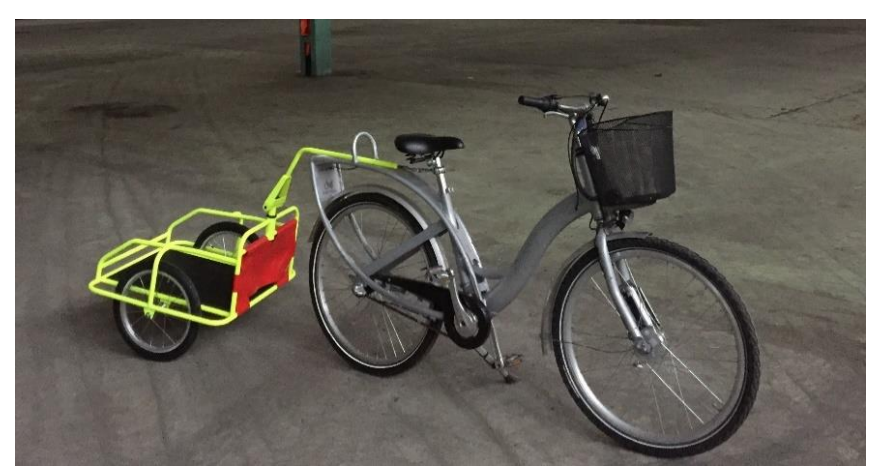

Figure 5. Cargo trailer designed for shared bicycles by Jan Libera. 


\section{Discussion and Conclusions}

The aim of this article was to determine the differences between the users of e-bike sharing, and e-scooter sharing systems, and the characteristics of their travel behaviour. Our results show that the public e-bike sharing system, MEVO, has been significantly more popular among Tricity citizens than e-scooter sharing systems. Unlike in the USA or other European cities, this cannot be attributed to a longer period of adaptation of this technology, as both types of systems were introduced to Tricity the same year.

Surveyed city residents did not see the usefulness of e-scooters, complained about their prices, and were concerned about safety, when asked about reasons discouraging them from riding. We found that e-scooter sharing companies could increase the number of users by improving the availability of their services, possibly by better distribution, rebalancing and increases in the sizes of their fleets. They could also organize actions that would popularize e-scooter riding, as many people never tried to use this kind of device. Authorities may also support e-scooter sharing by increasing safety (possibly by building better infrastructure and implementing legal regulations for the use of electric personal transporters).

The major factors discouraging people from using MEVO were small numbers of available e-bikes, using their own bicycle, their durability and quality. These results were similar to the study of Nikitas [29], who found bike ownership as the most important reason for not using BSS in Goteborg. Low availability of MEVO bicycles perceived by surveyed citizens can be attributed to big demand for BSS services and a relatively small number of e-bikes available.

The most important flow of MEVO system was small number of available bicycles caused by both size of the fleet and faultiness of delivered e-bikes. The costs of bigger fleet could be compensated by higher rental prices, which were not perceived as an important barrier by the majority of users and non-users of MEVO.

Scooter sharing users in Tricity are on average younger than e-bike sharing users. There were also no retired or disabled people riding e-scooters among our respondents. The gender gap was wider among of e-scooter sharing users than amid MEVO users, but in both cases there were less women riding vehicles than men. Our results regarding e-scooter and bike sharing in terms of gender equality stand in opposition of the conclusions of the Populus [14] report, which argued that the gap is actually smaller in case of e-scooters. We have also found that the share of people that own scooters and e-scooters was higher among users of e-scooter sharing services than amid other respondents.

Our research confirms the results published by McKenzie [18], He et al. [19], and Plazier et al. [21], that MEVO e-bikes were used to commute, while scooter sharing services were more often used for recreation. Results indicating leisure trips as the most common use of e-scooters are also consistent with the findings by Hardt and Bogenberger [20]. As ownership of own bicycles is a barrier to the use of e-bike sharing transportation, policy makers should promote public e-bikes as a part of a whole urban transportation system-first and last mile transportation mode supporting public buses, trams, etc. This can be achieved by improving the quality of passenger service at interchanges-better demand of e-bike fleet, safe infrastructure, integrated charging system for all urban transport services.

The major limitation of our research is that it was conducted only in one metropolitan area focusing merely on MEVO bikes and newly introduced e-shooter sharing. It was not possible to perform the same research in other cities, as Tricity was so far the only metropolitan area, where bike sharing system was based on e-bikes only. Further studies should determine if our results can be generalized to other cities and countries, especially in the field of e-scooter users characteristics, motivations, and habits.

Our study may be useful for municipal authorities that plan introduction of bike sharing systems based on e-bikes to understand the needs of their potential users and their behaviour. Successfully implemented micromobility in urbanised areas is important due to the EU cities' obligation to fulfil the sustainable transportation policy. Micromobility services might be the one of the steps to achieve this. This paper may be also valuable for operators of bike sharing and scooter sharing systems. It can help with the design of the system, infrastructure and help to correctly define a group of future users for marketing and popularization purposes. 
Author Contributions: Conceptualization, T.B. and A.W.; Formal analysis, T.B. and A.W.; methodology, T.B.; resources, T.B. and A.W.; writing-original draft preparation, T.B. and A.W.; writing-review and editing, A.W.; visualization, A.W.; project administration, T.B.; funding acquisition, T.B. and A.W. All authors have read and agreed to the published version of the manuscript.

Funding: This research was funded by the Faculty of Economics, University of Gdansk, project no. project: 539-E000-B441-20. The APC was funded by the Faculty of Economics, University of Gdansk.

Conflicts of Interest: The authors declare no conflict of interest.

\section{References}

1. Brown, A.E.; Klein, N.J.; Thigpen, C.; Williams, N. Impeding access: The frequency and characteristics of improper scooter, bike, and car parking. Transp. Res. Interdiscip. Perspect. 2020, 4, 100099. [CrossRef]

2. Shaheen, S.P.; Cohen, A. Shared Micromoblity Policy Toolkit: Docked and Dockless Bike and Scooter Sharing. UC Berkeley Transp. Sustain. Res. Cent 2019. [CrossRef]

3. Guidon, S.; Becker, H.; Dediu, H.; Axhausen, K.W. Electric Bicycle-Sharing: A New Competitor in the Urban Transportation Market? An Empirical Analysis of Transaction Data. Transp. Res. Rec. J. Transp. Res. Board 2019, 2673, 15-26. [CrossRef]

4. Shaheen, S.; Chan, N. Mobility and the sharing economy: Potential to facilitate the first-and last-mile public transit connections. Built Environ. 2016, 42, 573-588. [CrossRef]

5. Wang, K.; Akar, G.; Chen, Y.-J. Bike sharing differences among Millennials, Gen Xers, and Baby Boomers: Lessons learnt from New York City's bike share. Transp. Res. Part A Policy Pract. 2018, 116, 1-14. [CrossRef]

6. Zhang, Y.; Thomas, T.; Brussel, M.J.G.; Van Maarseveen, M.F.A.M. The characteristics of bike-sharing usage: Case study in Zhongshan, China. Int. J. Transp. Dev. Integr. 2017, 1, 245-255. [CrossRef]

7. Czech, P.; Turoń, K.; Urbańczyk, R. Bike-Sharing as an Element of Integrated Urban Transport System. In Advances in Intelligent Systems and Computing; Springer: Cham, Switzerland, 2018; Volume 631, pp. 103-111; ISBN 9783319623153.

8. Chen, F.; Turon, K.; Kłos, M.; Czech, P.; Pamuła, W.; Sierpiński, G. Fifth Generation of Bike-sharinng systems-examples of Poland and China. Sci. J. Sil. Univ. Technol. Ser. Transp. 2018, 99, 5-13.

9. Sperling, D.; Pike, S.; Chase, R. Will the Transportation Revolutions Improve Our Lives—or Make Them Worse? In Three Revolutions; Island Press/Center for Resource Economics: Washington, DC, USA, 2018; pp. 1-20.

10. Astegiano, P.; Fermi, F.; Martino, A. Investigating the impact of e-bikes on modal share and greenhouse emissions: A system dynamic approach. Transp. Res. Procedia 2019, 37, 163-170. [CrossRef]

11. Qiu, L.-Y.; He, L.-Y. Bike Sharing and the Economy, the Environment, and Health-Related Externalities. Sustainability 2018, 10, 1145. [CrossRef]

12. Turoń, K.; Sierpiński, G. Bike-sharing as a possibility to support Vision Zero. MATEC Web Conf. 2018, 231, 03005. [CrossRef]

13. Kijewska, K.; Iwan, S. The Implementation of Environmental Friendly City Logistics in South Baltic Region Cities. In Advances in Intelligent Systems and Computing; Springer: Cham, Switzerland, 2019; Volume 879, pp. 599-606; ISBN 9783030023041.

14. Populus. The Micro-Mobility Revolution: The Introduction and Adoption of Electric Scooters in the United States; Populus: San Francisco, CA, USA, 2018.

15. Akar, G.; Fischer, N.; Namgung, M. Bicycling Choice and Gender Case Study: The Ohio State University. Int. J. Sustain. Transp. 2013, 7, 347-365. [CrossRef]

16. Murphy, E.; Usher, J. The Role of Bicycle-sharing in the City: Analysis of the Irish Experience. Int. J. Sustain. Transp. 2015, 9, 116-125. [CrossRef]

17. Sanders, R.L.; Branion-Calles, M.; Nelson, T. To scoot or not to scoot: Findings from a recent survey about the benefits and barriers of using E-scooters for riders and non-riders. Transp. Res. Part A Policy Pract. 2020, 139, 217-227. [CrossRef]

18. McKenzie, G. Spatiotemporal comparative analysis of scooter-share and bike-share usage patterns in Washington, D.C. J. Transp. Geogr. 2019, 78, 19-28. [CrossRef]

19. He, Y.; Song, Z.; Liu, Z.; Sze, N.N. Factors Influencing Electric Bike Share Ridership: Analysis of Park City, Utah. Transp. Res. Rec. J. Transp. Res. Board 2019, 2673, 12-22. [CrossRef] 
20. Hardt, C.; Bogenberger, K. Usage of e-Scooters in Urban Environments. Transp. Res. Procedia 2019, 37, 155-162. [CrossRef]

21. Plazier, P.A.; Weitkamp, G.; van den Berg, A.E. “Cycling was never so easy!” An analysis of e-bike commuters' motives, travel behaviour and experiences using GPS-tracking and interviews. J. Transp. Geogr. 2017, 65, 25-34. [CrossRef]

22. Suchanek, M.; Szmelter-Jarosz, A. Environmental Aspects of Generation Y's Sustainable Mobility. Sustainability 2019, 11, 3204. [CrossRef]

23. Chen, M.; Wang, D.; Sun, Y.; Waygood, E.O.D.; Yang, W. A comparison of users' characteristics between station-based bikesharing system and free-floating bikesharing system: Case study in Hangzhou, China. Transportation (Amst.) 2018, 47, 689-704. [CrossRef]

24. Nikitas, A. Understanding bike-sharing acceptability and expected usage patterns in the context of a small city novel to the concept: A story of 'Greek Drama'. Transp. Res. Part F Traffic Psychol. Behav. 2018, 56, 306-321. [CrossRef]

25. Faghih-Imani, A.; Eluru, N. Analysing bicycle-sharing system user destination choice preferences: Chicago's Divvy system. J. Transp. Geogr. 2015, 44, 53-64. [CrossRef]

26. Bieliński, T.; Kwapisz, A.; Ważna, A. Bike-sharing systems in Poland. Sustainability 2019, 11, 2458. [CrossRef]

27. Lin, P.; Weng, J.; Liang, Q.; Alivanistos, D.; Ma, S. Impact of Weather Conditions and Built Environment on Public Bikesharing Trips in Beijing. Netw. Spat. Econ. 2019, 20, 1-17. [CrossRef]

28. Gebhart, K.; Noland, R.B. The impact of weather conditions on bikeshare trips in Washington, DC. Transportation (Amst.) 2014, 41, 1205-1225. [CrossRef]

29. Nikitas, A. How to save bike-sharing: An evidence-based survival toolkit for policy-makers and mobility providers. Sustainability 2019, 11, 3206. [CrossRef]

30. Bjørnarå, H.B.; Berntsen, S.; J te Velde, S.; Fyhri, A.; Deforche, B.; Andersen, L.B.; Bere, E. From cars to bikes-The effect of an intervention providing access to different bike types: A randomized controlled trial. PLoS ONE 2019, 14, e0219304. [CrossRef] [PubMed]

31. Urząd Statystyczny w Gdańsku. Available online: https://gdansk.stat.gov.pl/publikacje-i-foldery/ludnosc/ sytuacja-demograficzna-wojewodztwa-pomorskiego-w-2018-r-,3,2.html (accessed on 15 March 2020).

32. Michalski, L.; Jamroz, K.; Grzelec, K.; Grulkowski, S.; Kaszubowski, D.; Okraszewska, R.; Birr, K.; Kustra, W. Strategia Transportu i Mobilności Obszaru Metropolitalnego Gdańsk-Gdynia-Sopot do roku 2030; Obszar Metropolitalny Gdańsk-Gdynia-Sopot: Gdańsk, Poland, 2015.

33. Birr, K.; Birr, B.; Kostelecka, A. Raport monitoringowy do Strategii transportu i mobilności Obszaru Metropolitalnego Gdańsk Gdynia Sopot do roku 2030; Obszar Metropolitalny Gdańsk-Gdynia-Sopot: Gdańsk, Poland, 2018.

34. Kłos-Adamkiewicz, Z. Koszty i korzyści funkcjonowania miejskich wypożyczalni rowerów. Zeszty Nauk. Uniwerystyetu Szczecińskiego 2014, 26, 55-66.

35. Nextbike. Available online: https://nextbike.pl/pol-roku-mevo/ (accessed on 15 March 2020).

36. Szymczewski, A. trojmiasto.pl. Available online: https://dom.trojmiasto.pl/Mevo-oficjalnie-wystartowaloTest-aplikacji-n132966.html?id_news=132966\&strona=37\&vop=w (accessed on 15 March 2020).

37. Domaszewicz, Z. smartride.pl. Available online: https://smartride.pl/logo-sharing-wprowadza-kolejne-ehulajnogi/ (accessed on 15 March 2020).

38. trojmiasto.pl. Available online: https://aktywne.trojmiasto.pl/Elektryczne-hulajnogi-wjezdzaja-do-Trojmiastan133966.html (accessed on 15 March 2020).

39. elektrowoz.pl. Available online: https://elektrowoz.pl/transport/gdansk-dostal-elektryczne-hulajnogi-blinkeecity-cennik-25-zl-wypozyczenie-049-zl-min/ (accessed on 15 March 2020).

40. blinkee.city. Available online: https://blinkee.city/pl/about-us (accessed on 15 March 2020).

41. Shaheen, S.; Zhang, H.; Martin, E.; Guzman, S. China's Hangzhou Public Bicycle: Understanding early adoption and behavioral response to bikesharing. Transp. Res. Rec. 2011, 2247, 33-41. [CrossRef]

42. Du, M.; Cheng, L. Better understanding the characteristics and influential factors of different travel patterns in free-floating bike sharing: Evidence from Nanjing, China. Sustainability 2018, 10, 1244. [CrossRef]

43. Nocerino, R.; Colorni, A.; Lia, F.; Luè, A. E-bikes and E-scooters for Smart Logistics: Environmental and Economic Sustainability in Pro-E-bike Italian Pilots. Transp. Res. Procedia 2016, 14, 2362-2371. [CrossRef]

44. Gruber, J.; Ehrler, V.; Lenz, B. Technical Potential and User Requirements for the Implementation of Electric Cargo Bikes in Courier Logistics Services. In Proceedings of the 13th World Conference on Transport Research Society, Rio de Janeiro, Brasil, 13-18 July 2013; pp. 1-16. 
45. Gruber, J.; Thoma, L. Perception of Drivers and Barriers in the Adoption of Cargo Cycles by Private and Public Organizations in Germany. Transp. Res. Procedia 2019, 41, 395-397. [CrossRef]

46. Riggs, W. Cargo bikes as a growth area for bicycle vs. auto trips: Exploring the potential for mode substitution behavior. Transp. Res. Part. F Traffic Psychol. Behav. 2016, 43, 48-55. [CrossRef]

47. Melo, S.; Baptista, P. Evaluating the impacts of using cargo cycles on urban logistics: Integrating traffic, environmental and operational boundaries. Eur. Transp. Res. Rev. 2017, 9, 1-10. [CrossRef]

48. Becker, S.; Rudolf, C. Exploring the potential of free cargo-bikesharing for sustainable mobility. GAIA 2018, 27, 156-164. [CrossRef]

49. Schliwa, G.; Armitage, R.; Aziz, S.; Evans, J.; Rhoades, J. Sustainable city logistics-Making cargo cycles viable for urban freight transport. Res. Transp. Bus. Manag. 2015, 15, 50-57. [CrossRef]

50. Gruber, J.; Narayanan, S. Travel Time Differences between Cargo Cycles and Cars in Commercial Transport Operations. Transp. Res. Rec. 2019, 2673, 623-637. [CrossRef]

51. Hess, A.K.; Schubert, I. Functional perceptions, barriers, and demographics concerning e-cargo bike sharing in Switzerland. Transp. Res. Part. D Transp. Environ. 2019, 71, 153-168. [CrossRef]

52. Szymczewski, A. trojmiasto.pl. Available online: https://m.trojmiasto.pl/wiadomosci/Mevo-600-tys-zl-kardla-uzytkownikow-n135752.html (accessed on 15 March 2020).

53. Leite Nascimento, C.D.O.; Rigatto, I.B.; de Oliveira, L.K. Characterization and analysis of the economic viability of cycle logistics transport in Brazil. Transp. Res. Procedia 2020, 46, 189-196. [CrossRef]

54. Gruber, J.; Kihm, A.; Lenz, B. A new vehicle for urban freight? An ex-ante evaluation of electric cargo bikes in courier services. Res. Transp. Bus. Manag. 2014, 11, 53-62. [CrossRef]

Publisher's Note: MDPI stays neutral with regard to jurisdictional claims in published maps and institutional affiliations. 